\title{
On the Relationship between the IELTS Listening and Listening in Academic English Programs
}

\author{
Masood Khalili Sabet \\ Department of English, Faculty of Human Science and Literature, University of Guilan, I, R. Iran \\ E-mail: Sabetma@yahoo.com \\ Hamid Reza Babaei (Corresponding author) \\ Department of Teaching English as a Foreign Language, Faculty of Human Science and Literature, University of Guilan, I, R. Iran \\ E-mail: hreza86b@gmail.com
}

Doi:10.7575/aiac.alls.v.8n.2p.170

URL: http://dx.doi.org/10.7575/aiac.alls.v.8n.2p.170
Received: 02/03/2017

Accepted: 18/04/2017

\begin{abstract}
The challenge for many teachers teaching in academic English programs is, on the one hand, to actualize the objectives of their course and on the other hand, prepare their students for the important international tests such as IELTS and TOEFLE. The current study seeks to reconcile this challenge by drawing on the relationship between the IELTS listening and listening in academic English programs. The requirements of the two domains were compared through a semi - structured interview with five participating academic English instructors from two state universities of Iran. It was found that whilst IELTS listening bears a little bit of resemblance to the one aspect of academic listening - the literal understanding, there are also some very significant differences. The findings suggests that the type of listening the IELTS requires is different from academic listening in terms of pragmatic understanding, the integration of skills, multiplicity of texts for listening, information literacy and the concept of construct irrelevant variance. The findings also indicate the overall usefulness of the IELTS preparation practices within academic English courses.
\end{abstract}

Keywords: International tests; IELTS listening; Academic listening; English programs

\section{Introduction}

IELTS, international English language testing system is a testing program that assesses the language ability of candidates whose aim is education or work in an English speaking country (IELTS 10, 2015). The use of IELTS test has been expanded in recent years because of the increase in the number of the students willing to study in universities of English speaking countries and the overgrowing number of the universities requiring the IELTS as a prerequisite for the students (Moore \& Morton, 1999). This situation leads to the incorporation of the IELTS preparation courses within the English academic programs. (Moore \& Morton, 1999).

Listening in academic English programs is characterized by different perspectives. With regard to the listening for the purpose of the comprehension of the subject matter in the special field, it is characterized by one-way transactional language that aspires to get across information and knowledge (Flowerdew, 1994; Chaudron, 1995). In the case of the practices for daily routines and conversational listening, in addition to transactional facet of listening, it also includes the interactional domains of it. Whether the listening practices in academic English programs are transactional or interactional, it is significant to have a broad picture of the relationship between the IELTS and listening in these programs. Deakin (1997), in an Australian survey of the teachers' attitudes toward the IELTS, revealed that although there were positive answers to the test, almost half of those investigated believed that IELTS had an insignificant backwash impact on the listening practices in the university and academic English programs. However, the overgrowing increase in the number of the IELTS participants and universities demanding IELTS in recent years point to the increase in the degree of the possible wash back effect of the IELTS on the listening practices of university English programs.

The current study takes up the issue of the relationship between the IELTS listening and listening in academic English programs. Specifically, its purpose is to investigate the degree of the correspondence between the two domains and reveal the possible divergences and convergences among them in order to get a broader picture regarding the practices of listening in the two domains and the processes underlying them.

\section{Review of the literature}

\subsection{IELTS listening test}

The IELTS test in its current format is comprised of two modules (academic and general) each of them including four components: listening, reading, writing, and speaking. According to the IELTS handbook (2007) the IELTS test is made up of one type of listening test both in general training module and academic module. The listening component of the 
IELTS includes four sections. The first two sections assess the issues concerned with social needs. The first section is a dialogue occurred among two people and the second section is a monologue. The other two parts that are related with educational conditions test participants' ability in comprehension of speech expressed in didactic contexts. In this case, the third section is comprised of a dialogue occurring among more than four people and the fourth section is made up of a monologue. Along with the listening sections is a variety of tasks ( 40 in total) developed to test students understanding of the material in 30 minutes allocated. These tasks listed by IELTS 10 (2015) are: Multiple choice items, Short-answer questions, Sentence completion, Note/summary/flow chart/table completion items, Labeling a diagram/plan/map, Classification items, and Matching items.

\subsection{Previous studies of academic listening}

In recent years a number of university studies have been conducted to develop a picture of the type of listening and its' requirements in tertiary level. These studies can be divided into five domains. The first domain concerned with the effects of discourse structure on L2 academic listening. In this regard, it has been found that lectures with different subject matters have the different patterns of organization in discourse, and that the ignorance of the difference on organization yield understanding complexities on the part of the L2 learners (e.g., Olsen \& Huckin, 1990; DudleyEvans, 1994; Tauroza \& Allison, 1994; Young, 1994). Olsen and Huckin (1990) observed that L2 listeners couldn't get the gist of a lecture in spite of the sufficient command of English competence at the level of the sentence and pointed out that L2 learner's problems in understanding is dealt with the discourse level, not at the sentence level concerned with the linguistic insufficiency. Ta uroza and Allison (1994) also stated that the unfamiliarity of discourse patterns raises the possibility of failure in comprehension of the lectures. In the next domain, researchers investigated the impacts of the speech rate on academic listening. Griffiths (1990) proved that the speech expressed at a slow rate did not considerably differ from that of speech articulated at a normal rate, confirming that an unnaturally slow speech rate impede the process of listening. Zhao (1997) highlighted the importance of considering students as unique individuals for the better understanding of how speech rate is related to listening comprehension. The third domain related to the Functions of discourse markers in academic listening. In this case, it was found that L2 listeners have complexities in identifying the markers of different parts of text in L2 lectures (Yuan, 1982). Dunkel and Davis (1994) emphasized the trivial impact of discourse markers on the degree of information L2 listeners remembered. However, Flowerdew and Tauroza (1995) discovered that listeners understand the lecture better when micro-markers were shown to them. In the fourth domain, researchers studied impacts of note-taking on academic listening. Note-taking is instinctively engaging as an exterior storage for erudition and retention of text (DiVesta \& Gray, 1972). Many studies have been conducted in this domain (e.g., King 1994; Dunkel, Mischra, and Berliner, 1989; Chaudron, Loschky, and Cook, 1994; Hale and Courtney, 1994). Some of them have found the positive effect, while the others have confirmed the trivial effect of the note taking on academic listening. For example, Chaudron, Loschky, and Cook (1994) investigated the effect of recalling notes on L2 learners' understanding and the linkage between L2 listeners' understanding and their note value. They showed trivial impact for note recalling and weak connection between the note value and understanding. The last domain of the studies pertains the strategies utilized for comprehension of the academic listening. A vast majority of research has been conducted in this area. (e.g., Vandergrift, 1996; Bacon, 1992; Benson, 1989; O’Malley, Chamot, \& Kupper, 1989; Mason, 1994; Lynch, 1995 and etc). Overall, research has indicated the overall importance of the strategies for lecture comprehension and has also categorized the necessary strategies required for academic listening.

The present study is, in essence, a qualitative enquiry that considers the linkage between the IELTS listening and academic listening. This study differs from the studies mentioned above in two important ways. First, it is a comparative research which compares the correspondence of the requirements in the two domains of IELTS and academic listening. Second, it inclusively dealt with the listening in academic English programs and did not investigate the listening requirements of the other academic fields of the study.

\section{Method}

\subsection{Design}

Qualitative design has been planned for the study and tools of qualitative investigation were employed. According to Dornyei (2007) qualitative research includes data collection methods resulting mainly in unlimited, arithmetical data analyzed principally by non-statistical procedures. In this regard, for gathering the data required for the research, semi structured interview with academic instructors is employed (Appendix 1).

\subsection{Instruments}

In order to get a comprehensive picture of the relationship between listening requirements of the IELTS and academic domain, the current study employed semi - structured interviews with academic instructors. Five instructors were invited to participate in the study. Prior to the interviews, a schedule of questions along with a sample of IELTS listening test materials were sent to the listening instructors (see Appendix 1). The IELTS materials were selected so as to cover a representative sample of test tasks. The interview was made of two questions investigating: 1) the perceptions regarding the degree of correspondence between the academic listening requirements and those on the IELTS listening tasks, and 2) insights regarding the overall usefulness of the IELTS preparation practices in university English courses. The interview used in the study was Semi - structured one that permitted the researcher to quest the format known as the 'discourse-based interview' (Odell, Goswami \& Herrington, 1983). Such a technique includes discussion with instructors about the sample IELTS Listening test items. The interviews conducted for an average of one hour. All 
interviews were audio-recorded and transcribed in order to be further used as evidences for the various parts of the research. The main themes and ideas to arise from our instructors' comments are described in Section 4.1.

\subsection{Participants}

In order to obtain a picture of similarities and differences between the two domains, interviews were conducted in the two different state universities of Iran: university of Guilan and international university of Imam Khomeini in Qazvin. It was observed that, in university of Guilan two listening courses for undergraduate foreign language learners of English with a more focus on textbook-based listening materials were held. The other, international university of Imam Khomeini was observed to offer two listening courses with a more focus on internet-oriented listening materials. To collect the data, five listening instructors (three of them from university of Guilan and two of them from university of Imam Khomeini) from these two universities were invited to be interviewed in the research. A small number of participants were invited to participate in study for the purpose of examining the data more deeply and meticulously. Furthermore, the issues of the saturation and repetition were taken into consideration and new findings were unlikely to arise out of additional number of interviews. Since the interviews intended to shed light on the areas of similarities and differences between the two domains, it was essential that instructors participate with their full readiness in order to collaborate with the researcher maximally. All of the instructors were also observed to prescribe textbook in their courses. Four academic listening textbooks prescribed included: (1) Mosaic, (2) Real listening and speaking, (3) Tactics for listening and, (4) Lecture ready. It needs to be mentioned that Tactics for listening was common textbooks prescribed among the two of instructors.

\subsection{Data analysis and Procedure}

The study employed a semi - structured interview as a qualitative method for gathering data and examining the relationship between the IELTS and academic domains. The study was conducted in the following steps: first, to collect data necessary for the research, instructors from the 5 selected listening courses were contacted and invited to participate in the study. Second, interviews were conducted with the lecturers and participation included the deliverance of printed papers of questions and IELTS sample tasks contained in the interview (see Appendix 1); and recording the lecturers' voices for the further investigation. Finally, the voices were transcribed and analyzed for revealing the areas of the similarities and differences between the two domains.

\section{Findings from interviews - Comments on IELTS listening tasks}

In what follows, I turn to the replies from instructors in the interviews. As stated previously, the interview was made of two main questions, including consideration of: 1) insights concerning the congruence between listening requirements on listening courses and those on the IELTS listening test, and 2) insights regarding the overall usefulness of the IELTS preparation practices in university English courses. To facilitate discussion in the interview, instructors were provided with samples of IELTS listening tasks and requested to remark on hypothetical similarities and differences in listening requirements in the two realms (Appendix 1). They were also requested to contemplate on how advantageous they assume these sample IELTS listening tasks were likely to be as groundwork for the listening requirements of their courses. After scrutinizing commentaries, two groups of responses to these questions regarding the relationship between listening requirements in the two domains were identified. The first group of responses dealt with a less critical view of relationship and the second group concerned with the more critical view of the relationship between listening requirements in two realms.

The first group of informants (3 out of 5), who had a generally less critical view on the relationship between the IELTS test and study on their courses were lecturers from the University of Guilan and International University of Imam Khomeini who were using Tactics for listening and Mosaic textbooks in their courses. In general, these informants highlighted the effectiveness of training based on IELTS in their courses, while at the same time, expressed some reservations about its overall usefulness and general correspondence. The main reservation stated was a sense of a limited degree of congruence between the test and listening requirements in their courses, as seen in the following comments:

MOSAIC SERIES: When it comes to IELTS, there are some differences, we have some charts and diagrams like these here with missing information but they are kept to minimum in series [Mosaic]. So you might have charts and fill in the blanks items like these ones but as I said they are not highly emphasized [in mosaic].

TACTICS FOR LISTENING 1: The listening section in IELTS exam mostly is concerned with providing the input for completion tasks in which students are required to complete some forms, tables, and this is very difficult and requires multi-tasking. This is not the kind of task that students are trained for. At least, in the case of Iranian students, they are mostly familiar with the recognition tasks.

TACTICS FOR LISTENING 2: IELTS is an advanced level. Students who come to the university are new comers, they are not advanced. I mostly teach listening 1 and 2 and make them ready for advanced level. So IELTS is for advanced levels not for newcomers. 
In verifying these discrepancies, a significant theme commented by Mosaic lecturer among this group related to the importance of students' pragmatic understanding of certain key concepts and broader textual units of listening texts. The main theme pointed out was a sense of a limited degree of connection between the processes of listening required on IELTS test and those required on tasks set for academic courses, as commented in the following remarks:

MOSAIC SERIES: [in mosaic] the questions are not quite in line with IELTS as I mentioned as far as the purpose of test is concerned, but as far as the format is concerned there are some similarities. Most of them [questions] require kind of making inferences, a few items require factual information, they need to listen to a text, it might be conversation or lecture, and then there are some inferential and referential questions. The focus is on pragmatic understanding.

Whilst pinpointing processing differences between the listening skills in the two realms, this lecturer acknowledged that it would be most difficult to level criticism on IELTS exam without gathering empirical data, although he criticized scoring part of the IELTS exam in an imperceptible way through the face validity.

MOSAIC SERIES: I think it's very difficult to say something about the problems of IELTS. Because it's problematic and requires empirical data, I would rather not to talk about the quality of LELTS. Because they are validated tests. You can say something about the face validity, [but] it can't be much helpful. [But], when it comes to rating the issue of for example, weather in such cases spelling can be taken into consideration [or not].

Whilst emphasizing the differences between the requirements of IELTS and those of academic listening, the instructors from this 'less-critical oriented' group agreed that IELTS would be an indisputably valuable form of training for university study:

MOSAIC: I think IELTS would be very useful, here because American listening textbook [Mosaic] is mainly deal with the TOFLE. I think in any kind of conversation course, there should be one TOEFLE or IELTS, they are both proficiency test, they are not basically distinct in terms of the format, but there might be difference in terms of the skills and knowledge to be tested. So that's a must, I think after two or three sessions there should be a session dealing with samples of items of proficiency tests.

TACTICS FOR LISTENING 1: You know because they are not familiar with these kinds of tasks, having a kind of course focusing on these tasks-types would better prepare students for those tasks and give them enough opportunity and experiences for task-types, because they don't have any prior experience for [these] task types.

TACTICS FOR LISTENING 2: It is useful [to use IELTS]; we use the same IELTS test for advanced level in the university. It is reliable and valid.

In this case, the overwhelming importance of training the IELTS in academic courses was commented most unequivocally by Tactics for listening instructors. In a similar vein, they saw the development of skills required to response to the IELTS test as a key part of students' professional education in overseas and their emigration to the abroad.

TACTICS FOR LISTENING 1: I think we have to include these task-types, because IELTS exam is an international exam, most students in Iran are required to participate if they are going to emigrate to study in the abroad, so this play a very important role in students' academic life. So if we want to make listening classes useful, we have to incorporate some of these task-types into our comprehension classes.

TACTICS FOR LISTENING 2: It is useful because, some of students are ambitious, they want to continue their further education in Australia, Canada and native speaking countries. So when they come to advanced levels we use the same [IELTS] tests, first of all they want to go overseas, they have to pass IELTS, so it is very effective to make them to use the same test in order to make them ready for the IELTS and TOEFLE exam.

The other group - a slightly smaller one than the previous one - had a more critical opinion of the test and its probable effectiveness. This group was limited to just two instructors - Real listening and speaking, and lecture ready instructors. The overall view commented by these informants was that the purpose, hence, the construct of listening in 
the IELTS listening test was somehow at odds with that which functioned in listening tasks set at academic courses, and that, as an outcome, the test ventured delivering students a distorted impact of the nature of real listening.

REAL LISTENING AND SPEAKING: The purpose is different. Several times we work on one text that is different; it's not the problem with the IELTS, of course that's the nature of things that would be different. If you repeat everything for students, for teaching it's not a problem but when they are tested according to just strict form they have no opportunity to ask for clarification and whenever there is a test this might be a problem for any test of listening separate from speaking, [because] in real context they are included together, so that would be a problem of any test.

One other difference commented by this lecturer was the lack of variety in the LELTS tasks in comparison with the exercises included in the textbook and used in his classroom.

REAL LISTENING AND SPEAKING: The other thing is the lack of variety in the tasks of IELTS. In the textbook used in my classes, there are lots of variety, but the listening of IELTS, [is] fixed format, [there are] four tasks, the last one would be a lecture.

For Lecture ready informant, the focus was on the issue of the variety of topics in the case of IELTS and academic tasks. In this regard, she pointed out that an inequitable variety of topics in task-types set in two domains and irrelevancy of the topics to the listeners' background knowledge in the case of IELTS tasks, lead them to the additional variation.

LECTURE READY: The other thing is that students in the class would find the lectures for example relevant to them but in IELTS the lecture can be on any topic. For example about the extinction of animals that is good for students of biology not for students of language perhaps. [Thus] Variety of topics would be the difference, we have got variety of activities that they would be relevant to the students. In IELTS, [they're] not always relevant.

Moreover, more ominously this informant went on to level some criticisms on the listening part of the IELTS exam. One of the criticisms concerned with the isolation of listening from speaking in IELTS, whereas according to her they can't be separable in real context:

LECTURE READY: It is in isolation, I mean that it is not [integrated with speaking], because in my course it's listening and speaking together inseparable. In real context when you don't get one point you can use strategies to communicate and ask for clarification, but it is missing in test of IELTS.

The other shortcoming was dealt with the predictability of some items:

REAL LISTENING AND SPEAKING: very good test, but part of it can be predicted, because for example section on is only details of numbers, these are useful but it can be predictable.

Additional pitfall leveled on the notion of background knowledge. According to Real listening and speaking instructor, students' familiarity with the topic of the talk would impact their performance on the test and therefore generate construct - irrelevant variance:

REAL LISTENING AND SPEAKING: If students have background knowledge regarding the topic, they perform better on that IELTS section. But IELTS claims that no background knowledge would be required for listening sections, but in reality you see that it would affect their listening comprehension.

The last concern of the Real listening and speaking instructor related more to what he saw as the non-authentical nature of listening in the IELTS test. In his view, the problem lies on the scoring of spelling that is not in line with the real context in which listeners can understand even without knowing the correct spelling of all words. Whereas, what was notable about listening in real context and at university, he thought, was that it usually integrates with speaking together and can operate no matter if the spelling is understood or not, one which even is comprehended by the listeners' paraphrase of incoming stimuli. This, he thought, was a feature strongly lacking in the IELTS test and would lead to the unreliability of the test.

REAL LISTENING AND SPEAKING: In listening if you get the paraphrase to understand and use more words it doesn't hurt the communication, so some differences between this type of testing because if you get the spelling wrong, 
you get a low score, while I listening in real listening and speaking you don't need to have correct spelling. But one problem with the reliability is that they are supposed to write if spelling is wrong then they are not given any score that is a problem, exact method of spelling, so what is the difference between somebody who doesn't get the word and somebody who understand the meaning, get the word and misses the spelling. Spelling is another activity and other kind of skill, not essential for listening and understanding.

For this more 'critically-disposed' instructor, the sense of incongruity between listening demands in the two domains, as well as the test's perceived problems led him to believe that IELTS would not be an absolutely beneficial form of preparation for academic courses:

REAL LISTENING AND SPEAKING: I think if it is the only thing you work in class for preparation for IELTS, that won't work, because there is a difference between test and task. Tasks or exercises would be useful for learning, improvement, and development. But if it is the test only and all the activities are based on IELTS, [it won't work], you know that the aim of the test is measurement. But it is not good if you measure the students all the times. What about the teaching and learning and progress. What about other aspects of communication. If you overemphasize a kind of test for your classes then you lose sight of lots of important things.

\section{Conclusion}

The study showed the critical view of the relationship between the IELTS listening and listening in academic English programs. Whilst, the main similarity was revealed in those tasks of IELTS and academic domains requiring mainly bottom up engagement with the material, in many parts the two domains were identified to deviate from each other. The divergence between the two domains was verified in the interview commentaries of instructors where, for example, Mosaic lecture saw the critical understanding of the material as the main listening requirement in his course. Therefore, as we saw in investigation of the commentaries, concerns expressed regarding the differences between the listening requirements of two domains were identified to be prominent, whilst, on the other hand commentaries about the similarities kept to minimum. In sum, this prominence of viewpoints regarding the divergence of listening requirements in the two domains points to the more discrepancy of constructs than the similarity of them between the IELTS listening and academic listening.

Another difference was difference in listening to the number of texts, that in contrast to the IELTS, academic listening was identified to require listening to multiple texts. Such a view of multiplicity in engagement was confirmed in the interviews, where some instructors highlighted the engagement with different topics and sources as requirements for their courses that would develop students' listening skills in familiarity with various sources and different varieties of a language. As one instructor explained it, to give their presentation, students should "search for the sources, different varieties of English on different topics and they need to be responsive" about their presentation. Concern was also noted regarding the absence of the listening-speaking connections in the sample IELTS materials provided, and instructors wondered whether this feature of academic listening pointing to the other divergence between two domains, could be incorporated into the IELTS test somehow. Listening in the two domains was also perceived to vary around the notion of what Shapiro and Hughes, (1996) termed, 'information literacy' approach. In this case some instructors highlighted the importance of students' involvement in the variety of sources for the purpose of making them familiar with the different means of getting information from different sources such as online and media. In contrast, it was identified that to a greater extent, the skills regarding the searching and selecting of sources seemed to have little or no manifestation in the IELTS listening test.

The last difference between the two domains can be explained with regard to the issue of construct irrelevant variance. According to Fulcher (2010) construct irrelevant variance is the effect of any unintended factor like noise and cheating on test scores that leads to the divergence between test scores and, hence, differentiation among students' performance due to the constructs in which we are not interested. The analysis of commentaries expressed in interviews revealed some unintended variables underlying IELTS test that effect test takers' listening test score in particular and their overall test score in general and make an incredible difference among them, hence leading to the construct-irrelevant variance between scores. In this sense, the variables identified to be: 1. Scoring procedure; 2 . lacking variety; 3. disintegration of listening and speaking; 4. predictability of some items.

Overall, the research has revealed a number of differences between the requirements of listening in the two domains. Arguably, as one of the instructors expressed; the significant reason for the differences lie at the center of the difference between the notions of the task and the test. In the IELTS corpus all tasks were identified to be necessarily tests, while in university context, by contrast, almost all tasks were identified to be set for improvement, not for assessment. Therefore this difference leads to difference in the requirements of the two domains.

\section{References}

Benson, M. (1989). The academic listening task: A case study. TESOL Quarterly, 23, 421-445.

Chaudron, C. (1995). Academic listening. In D. J. Mendelsohn \& J. Rubin (Eds.), A guide to the teaching of second language listening (pp. 77-96). San Diego: Dominie. 
Chaudron, C., Loschky, L., \& Cook, J. (1994). Second language listening comprehension and lecture note-taking. In J. Flowerdew (Ed.), Academic listening: Research perspectives (pp. 75-92). New York: Cambridge University Press.

Deakin, G. (1997). IELTS in context: Issues in EAP for overseas students. EA Journal, 15, 7-28.

DiVesta, F., \& Gray, S. (1972). Listening and note taking. Journal of Educational Psychology, 63, 8-14.

Dornyei, Z. (2007). Research methods in applied linguistics. (1rd ed.). Oxford: Oxford university press. (Chapter 2).

Dudley-Evans, T. (1994). Variations in the discourse patterns favored by different disciplines and their pedagogical implications. In J. Flowerdew (Ed.), Academic listening: Research perspectives (pp. 146-158). New York: Cambridge University Press.

Dunkel, P. A., Mischra, S., \& Berliner, D. (1989). Effects of note taking, memory, and language proficiency on lecture learning for native and nonnative speakers of English. TESOL Quarterly, 23, 543-549.

Dunkel, P. A., \& Davis, J. N. (1994). The effects of rhetorical signaling cues on the recall of English lecture information by speakers of English as a native or second language. In J. Flowerdew (Ed.), Academic listening: Research perspectives (pp. 55-74). New York: Cambridge University Press.

Flowerdew, J. (1994). Academic listening: Research perspectives. New York: Cambridge University Press.

Flowerdew, J., \& Tauroza, S. (1995). The effect of discourse markers on second language lecture comprehension. Studies of Second Language Acquisition, 17, 435-458.

Griffiths, R. T. (1990). Speech rate and NNS comprehension: A preliminary study in time-benefit analysis. Language Learning. 40. 311-336.

Hale, G. A., \& Courtney, R. (1994). The effects of note-taking on listening comprehension in the test of English as a foreign language. Language Testing, 11, 29-46.

IELTS. (2007). The IELTS handbook, UCLES/British Council, IDP Education Australia: Cambridge.

IELTS 10. (2015). Examination papers from University of Cambridge ESOL examinations. Cambridge: Cambridge University of Press. (4 x Listening tests).

King, P. (1994). Visual and verbal messages in the engineering lecture: note taking by postgraduate L2 students. In J. Flowerdew (Ed.), Academic listening: Research perspectives (pp. 219-238). New York: Cambridge University Press.

Lynch, T. (1995). The development of interactive listening strategies in second language academic settings. In D. J. Mendelsohn \& J. Rubin (Eds.), A guide to the teaching of second language listening (pp. 166-185). San Diego: Dominie.

Mason, A. (1994). By dint of: Student and lecturer perceptions of lecture comprehension strategies in first-term graduate study. In J. Flowerdew (Ed.), Academic listening: Research perspectives (pp. 199-218). New York: Cambridge University Press.

Moore, T., and Morton, J. (2007). .Authenticity in the IELTS Academic Module Writing Test: A

comparative study of Task 2 items and university assignments. In L. Taylor and P. Falvey (Eds.), IELTS collected papers: Research in speaking and writing assessment (pp. 197-248). Cambridge: Cambridge University Press.

Odell, L, Goswami, D., and Herrington, A. (1983). The discourse-based interview: A procedure for exploring the tacit knowledge of writers in nonacademic settings. In P. Mosenthal, L. Tamor and S. Walmsley (Eds.), Research on in Research on writing: Principles and methods (pp. 221- 236). New York: Longman.

Olsen, L. A., \& Huckin, T. N. (1990). Point-driven understanding in engineering lecture comprehension. English for Specific Purpose. 9. 33-47.

O'Malley, J. M., Chamot, A. U., \& Kupper, L. (1989). Listening comprehension strategies in second language acquisition. Applied Linguistics. 10. 418-437.

Shapiro, J and Hughes, S. (1996). Information literacy as a liberal art. Educom Review, 31(2), 31-35.

Tauroza, S., \& Allison, D. (1994). Expectation-driven understandings in information systems lecture comprehension. In J. Flowerdew (Ed.), Academic listening: Research perspectives (pp. 35-54). New York: Cambridge University Press.

Vandergrift, L. (1996). The listening comprehension strategies of core French high school students. The Canadian Modern Language Review, 52, 200-223.

Bacon, S. (1992). The relationship between gender, comprehension, processing, strategies, and cognitive and affective response in foreign language listening. The Modern Language Journal, 76, 160-178.

Young, L. (1994). University lectures-macro-structure and micro-structure. In J. Flowerdew (Ed.), Academic listening: Research perspectives (pp. 159-176). New York: Cambridge University Press.

Yuan, D. Z. (1982). Chinese scientists' difficulties in comprehending English science lectures. Unpublished master thesis. University of California, Los Angles.

Zhao, Y. (1997). The effects of listener's control of speech rate on second language comprehension. Applied Linguistics, 18, 49-68. 
Appendix 1: Semi-structured Interview Protocol

The fallowing questions are concerned with the comparisons between the assignment tasks you provided and the attached sample IELTS listening tasks.

1. What do you see as the main similarities and/or differences between the type of listening set on the IELTS test, and the type of listening you require of your students on the course?

2. On the evidence of these IELTS tasks, to what extent do you think training for the IELTS listening test would be useful preparation for the listening demands on your course? Explain.

\section{Sample IELTS listening test material:}

\section{Test 1}

\section{LISTENING}

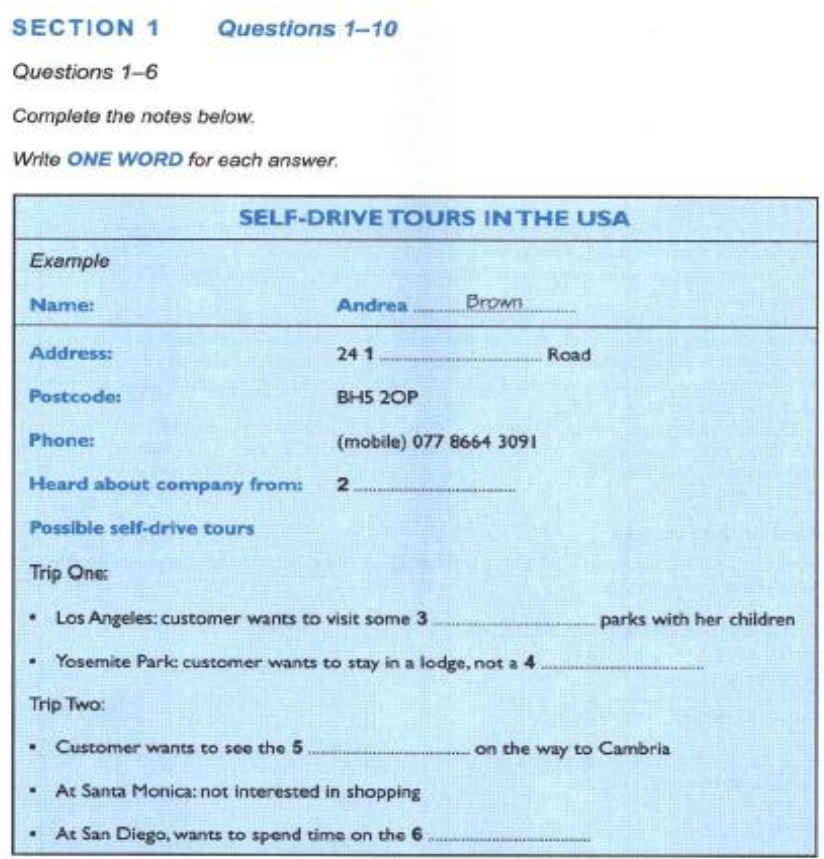

10

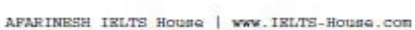

Questions 7-10

Complete the table below.

Wite ONE WORD AND/OR A NUMBER for each answer.

\begin{tabular}{|c|c|c|c|c|}
\hline & $\begin{array}{l}\text { Number } \\
\text { of days }\end{array}$ & Total distance & $\begin{array}{c}\text { Price } \\
\text { (per person) }\end{array}$ & Includes \\
\hline Trip One & 12 days & $7 \longrightarrow \mathrm{km}$ & $£ 525$ & $\begin{array}{l}\text { - accommodation } \\
\text { - car } \\
\text { - une } 8\end{array}$ \\
\hline Trip Two & 9 days & $980 \mathrm{~km}$ & $9 E_{\ldots}$ & $\begin{array}{l}\text { - accommodation } \\
\text { - car } \\
\text { - } 10\end{array}$ \\
\hline
\end{tabular}




\section{SECTION 2 Questions 11-20}

Questions 11-12

\section{Choose TWO letters A-E.}

Whirh TWO facilities at the leisure club have recently boon improved?
A the gym
B the tracks
C the indoor pool
D the outdoor pool
E the sports training for children

\section{Questions 13-20}

\section{Complete the notes below.}

Write NO MORE THAN TWO WORDS for each answer.

\section{Joining the leisure club}

Personal Assessment

- New members should describe any $\mathbf{1 3}$

- The 14 ................. we explained to you before you use the equipment.

- You will be given a six-week 15

Types of membership

- There is a compulsory $£ 9016$ fee for members.

- Gold members are given 17 to all the LP clubs.

- Premier members are given priority during $\mathbf{1 8}$ hours.

- Premier members can bring some 19 _........................ every month.

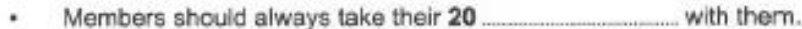

\section{SECTION 3 Questions 21-30}

Questions 21-25

Choose the correct letter, A, B or C.

\section{Global Design Competition}

21 Students entering the design competition have to

A produce an energy-efficient design.

B adapt an existing energy-saving appliance,

C develop a new use for current technology.

22 John chose a disl washer because he wanted to make dishwashers
A more appealing.
B more common.
C more economical.

23 The stone in John's 'Rockpool' design is used
A for decoration.
B to switch it on.
C to stop water oscaping.

24 In the holding chamber, the carbon dioxide
A changes back to a gas.
$B$ dries the dishes.
C is allowed to cool.

25 At the end of the cleaning process, the carbon dioxide
A is released into the air.
B is disposed of with the waste.
C is collected ready to be ra-used 


\section{Questions 26-30}

Complete the notes below.

Write ONE WORD ONLY for each answer.

- John needs help preparing for his 26

- The prolessor advises John to make a 27 of his design

- John's main problem is getting good quality 28

- The professor suggests John apply for a 29

- The professor will check the 30 information in John's written report.

\section{SECTION 4 Questions 31-40}

Complete the notes below.

Write ONE WORD ONLY for each answer.

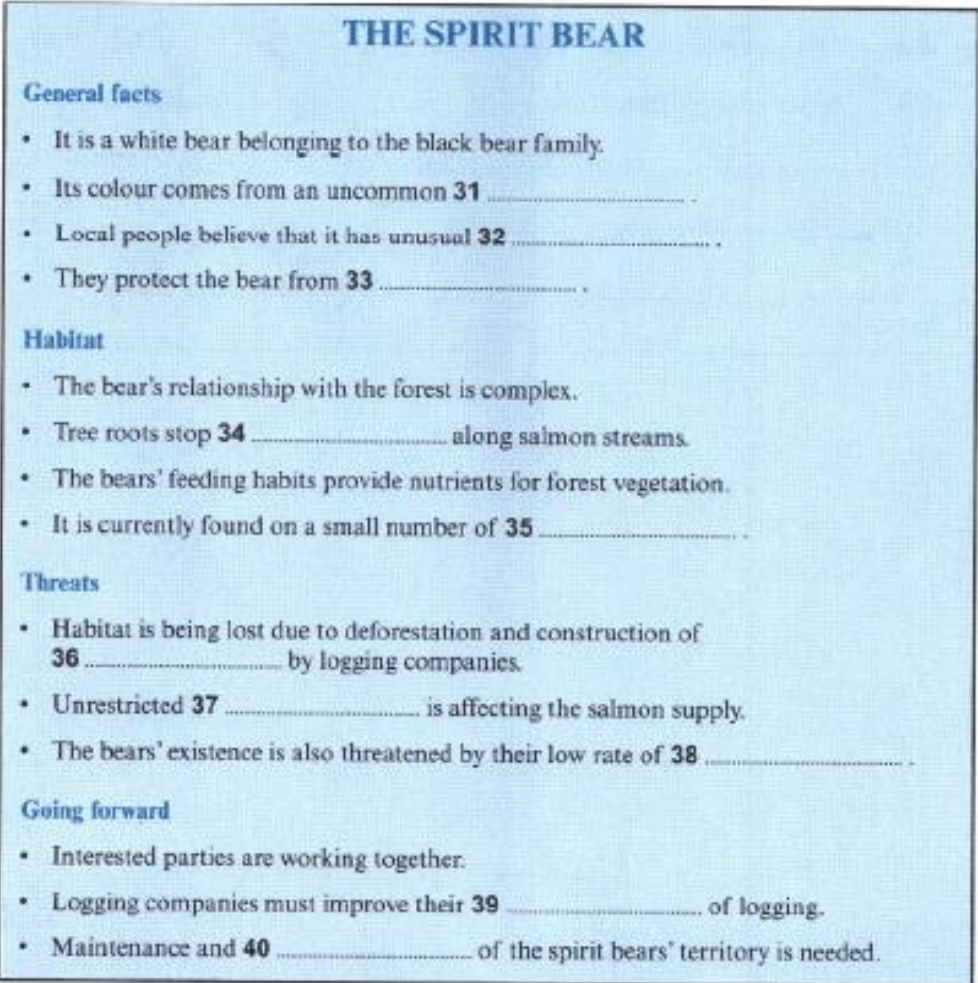

